sensoล̊s] Cally

Subscriber access provided by Caltech Library

\title{
Letter
}

\section{Superwettable Electrochemical Biosensor toward Detection of Cancer Biomarkers}

Tailin Xu, Yongchao Song, Wei Gao, Tingting Wu, Li-Ping Xu, Xueji Zhang, and Shutao Wang

ACS Sens., Just Accepted Manuscript • DOI: 10.1021/acssensors.7b00868 • Publication Date (Web): 08 Jan 2018

Downloaded from http://pubs.acs.org on January 8, 2018

\section{Just Accepted}

"Just Accepted" manuscripts have been peer-reviewed and accepted for publication. They are posted online prior to technical editing, formatting for publication and author proofing. The American Chemical Society provides "Just Accepted" as a free service to the research community to expedite the dissemination of scientific material as soon as possible after acceptance. "Just Accepted" manuscripts appear in full in PDF format accompanied by an HTML abstract. "Just Accepted" manuscripts have been fully peer reviewed, but should not be considered the official version of record. They are accessible to all readers and citable by the Digital Object Identifier (DOI®). "Just Accepted" is an optional service offered to authors. Therefore, the "Just Accepted" Web site may not include all articles that will be published in the journal. After a manuscript is technically edited and formatted, it will be removed from the "Just Accepted" Web site and published as an ASAP article. Note that technical editing may introduce minor changes to the manuscript text and/or graphics which could affect content, and all legal disclaimers and ethical guidelines that apply to the journal pertain. ACS cannot be held responsible for errors or consequences arising from the use of information contained in these "Just Accepted" manuscripts. 
Inspired by extreme states of solid surface wettability in nature, considerable efforts have been devoted to the development of materials with superwettable properties for diverse applications. ${ }^{1-7}$ Recently, superwettable materials have been proved to have outstanding capacity in controlling liquid droplets, such as their directional motion on anisotropic wettable surface and droplets transferring between surfaces. ${ }^{8-10}$ Importantly, superwettable microchips that combine two extreme states of superhydrophobicity and superhydrophilicity in precisely two-dimensional micropatterns, ${ }^{11-14}$ exhibit excellent ability of patterning microdroplets toward new possibilities and functionalities in a wide variety of biomedical applications including high-throughput cell patterns, ${ }^{15-}$ ${ }^{18} \mathrm{drug} / \mathrm{cell}$ screening, ${ }^{19-21}$ and open-channel biochips for separation and diagnostic devices. ${ }^{22-25}$ Taking advantage of enrichment and anchoring microdroplet ability of such superwettable microchips, recent efforts have shifted to modify the superhydrophilic microwells with biological entities, toward more versatile and

\begin{abstract}
Bioinspired superwettable micropatterns that drophilicity with the ability of enrichment and absorbing microdroplet are suitable for versatile and robust sensing applications.
Here we introduce a superwettable microchip that integrates superhydrophobic- superhydrophilic micropatterns and nanodendritic electrochemical biosensor toward detection of prostate cancer
biomarkers. On the superwettable microchip, the superhydrophobic area could confine the microdroplets in superhydrophilic microwells, such behavior is extremely helpful for reducing the
amount of analytical solution. In contrast, superhydrophilic microwells exhibit a high adhesive force toward microdroplets, and the nanodendritic structures can improve probe-binding capacity
and the response signals, thus greatly enhancing the sensitivity. Sensitive and selective detection of prostate cancer biomarkers including miRNA-375, miRNA-141 and prostate-specific antigen
on single microchip is also achieved. Such superwettable microchip with high sensitivity, low sample volume and upside-down detection capability in a single microdroplet, shows great potential
to fabricate portable devices toward complex biosensing applications.
\end{abstract}

robust sensing applications. As a result, several types of superwettable microchips have been explored depending on different detection signals such as surface-enhanced Raman scattering (SERS) ${ }^{26-28}$ colorimetric, ${ }^{29-33}$ and fluorescence enhancement effect, ${ }^{34-36}$ to perform demanding sensing tasks. ${ }^{37-39}$

Electrochemical biosensors, as one of the most common methods of analytical research, have been widely used to sensitively detect biomolecules, ${ }^{40-43}$ such as glucose, ${ }^{44}$ nitric oxide, ${ }^{45}$ hydrogen peroxide, ${ }^{46}$ hydrogen sulfide, ${ }^{47}$ DNA /miRNA, ${ }^{48-50}$ and proteins. ${ }^{51}$ However, electrochemical biosensing are usually carried out in a large solution system. Here we demonstrate a superwettable electrochemical biosensor that integrates superwettable substrate for managing microdroplets with conductive nanodendritic electrochemical biosensor for sensitive measurement, toward detection of multiple prostate cancer biomarkers including miRNA-375, miRNA-141 and prostate-specific antigen. Such superwettable electrochemical biosensor bridges the gap between sensitive electrochemical biosensing and superwettable droplet management approach, showing great potential in highly sensitive and low-sample-volume detection within a single microdroplet.

Combining electrochemical deposition and template $\mathrm{O}_{2}$ plasma etching technology, superwettable electrochemical sensors with patterned superhydrophobic-superhydrophilic microarrays were fabricated as detailed in Fig. 1. Firstly, the nanodendritic gold substrate was fabricated according to previous literatures as following steps (Fig. 1a). ${ }^{52,53}$ Indium tin oxide (ITO) substrate was cut into small rectangular pieces $(1 \mathrm{~cm} \times 2 \mathrm{~cm})$, and ultrasonically cleaned for $10 \mathrm{~min}$ in deionized water, acetone, ammonia aqueous, and deionized water sequentially, to remove the organic matters and then dried with a flow of nitrogen. Before electrochemical deposition, a titanium layer and a gold film were sputtered on conductive side of the ITO substrate to serve as a working electrode for electrochemical deposition processes. $\mathrm{Ag} / \mathrm{AgCl}$ wire and Pt wire were employed as reference and counter electrodes, respectively. All electrochemical deposition steps were carried out at room temperature $\left(25^{\circ} \mathrm{C}\right)$. Gold nanodendritic structures were then electrodeposited at $-1.8 \mathrm{~V}$ for $1800 \mathrm{~s}$ in an electrolyte composed of $\mathrm{HAuCl}_{4}(1 \mathrm{mg} / \mathrm{mL})$ and sulfuric acid $(0.5 \mathrm{M})$. After electrochemical deposition, the superhydrophobic-superhydrophilic micropatterns were prepared as shown in Fig. 1b. Firstly, the dendritic gold nanostructure 
a
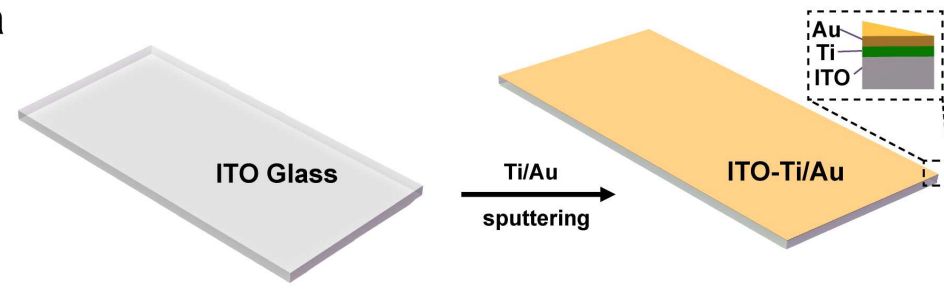

$\underset{\text { Electrodeposition }}{\stackrel{\mathrm{HAuCl}_{4}}{\longrightarrow}}$

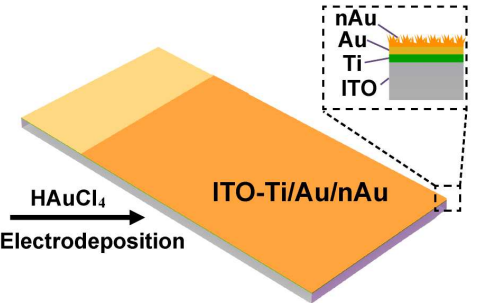

$\mathrm{O}_{2}$ Plasma

b

\section{C}

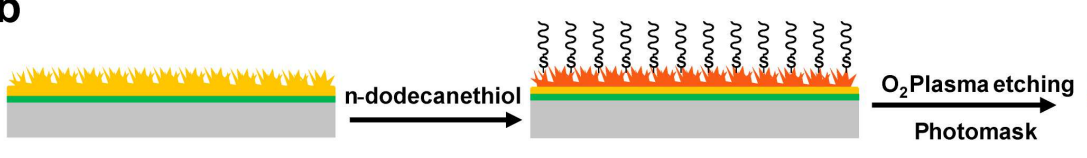

Superhydrophobic surface

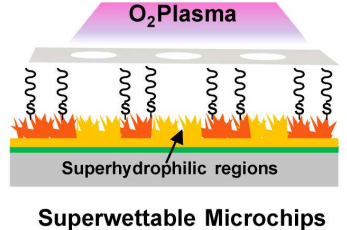

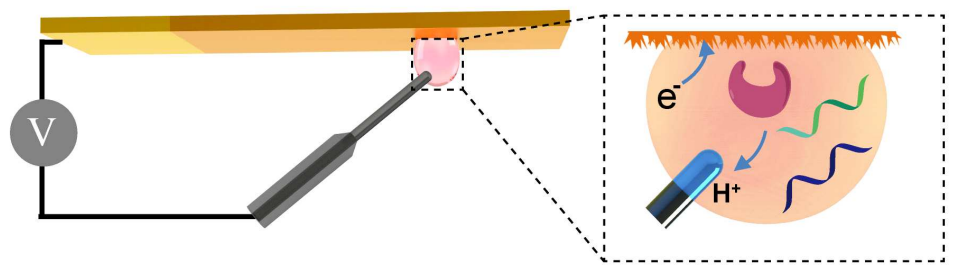

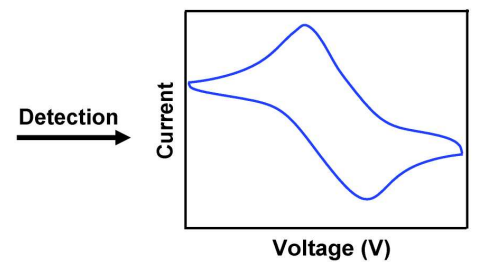

Figure 1: Design of superwettable electrochemical microchip towards biosensing. a) Fabrication of nanodendritic gold substrate including vapor deposition of Ti/Au thin film and electrochemical deposition gold nanodendrites. b) Modification of nanodendritic gold substrate to achieve conductive superhydrophobic-superhydrophilic surface. c) Schematic of electrochemical detection of analyte in droplets on the superwettable electrochemical microchip.

was treated with oxygen plasma at $100 \mathrm{~W}$ for $180 \mathrm{~s}$ for removing the organic matters, and then immersed in a dodecanethiol solution ( 10 vol. $\%$ in ethanol) for $24 \mathrm{~h}$ at room temperature. The dodecanethiol-modified substrate was cleaned by rinsing in ethanol and ultrapure water, respectively. Oxygen plasma at $100 \mathrm{~W}$ was used to irradiate the dodecanethiol-modified substrate through a photomask for $120 \mathrm{~s}$. The non-irradiated region remained superhydrophobic. In contrast, the oxygen plasma irradiated regions became superhydrophilic. Thus, we prepared the superwettable electrochemical biosensor.

The superwettable microchip integrate conductive gold superwettable substrate with electrochemical biosensors, showing great ability of holding microdroplets toward biosensing as shown in Fig 1c. Compared to flat glass without any modifications, the superhydrophilic microwells with nanodendritic structures exhibit a larger adhesive force to hold water microdroplets due to the capillary force of each individual nanostructure. As a result, microdroplets could be captured in the microwell against gravity. ${ }^{32}$ In contrast, the dodecanethiol-modified superhydrophobic area prevents water adhering on surface and confines the microdroplets in superhydrophilic microwells, greatly reduceing the amount of analytical solution. In addition, due to the large surface area, multi-directionality and 3D nanostructure of the nanodendritic electrode surface, the probe-binding capacity and the response signals of the sensor are also greatly improved (SI Fig. 2) .

The gold electrode fabricated by electrochemical deposition method was confirmed by SEM images as illustrated in Fig. 2a. The as-prepared electrode exhibited a highly branched structure (about 10-100 nm), the height of these branched structure is up to about $10 \mu \mathrm{m}$ (SI Fig. 1). Fig. 2b illustrates the contact angle of gold nanodendrites with or without dodecanethiol modification. Without any modification, the contact angle of gold nanodendrites is about $0^{\circ}(\mathbf{F i g} . \mathbf{2 b})$, while the contact angle of dodecanethiolmodified gold nanodendrites is $151.9 \pm 1.6^{\circ}$. Methyl blue labelled microdroplets on the as-prepared substrate present two diametrically opposed appearances as shown in Fig. 2c. On the dodecan- ethiol-modified surface, microdroplet is almost spherical and indicates its superhydrophobicity. In contrast, microdroplet is flattened in microwells, revealing its superhydrophilicity. In addition, we also evaluated the wettability of bare Au before and after the modification of dodecanethiol (Fig. 2d). For Au substrate with or without dodecanethiol modification, the contact angles are 58.6 $\pm 2.5^{\circ}$ and $98.4 \pm 2.0^{\circ}$ respectively, which shows a relatively small differences.
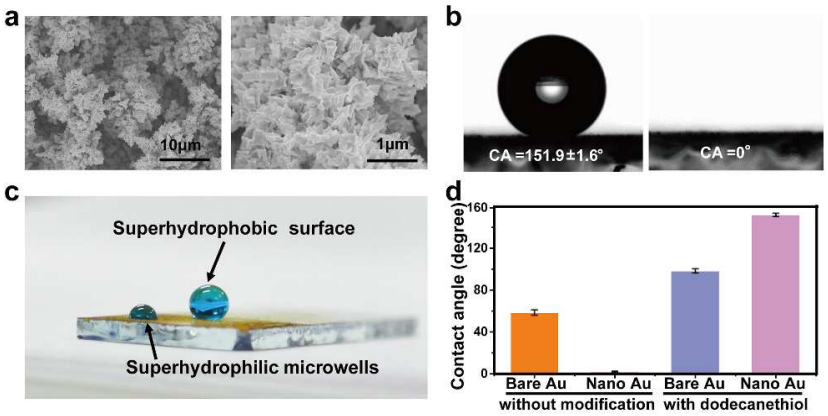

Figure 2: Physical characterization of the superwettable electrochemical microchip. a) SEM images of the gold nanodendrites. b) Microscope images of water contact angle of dodecanethiol modified gold nanodendrites (left) and after $\mathrm{O}_{2}$ plasma etching (right). c) Methyl blue labelled water microdroplets behavior on the thiolmodified superhydrophobic gold nanodendrites and on superhydrophilic microwells. d) Comparison of the contact angles of bare $\mathrm{Au}$ and $\mathrm{Au}$ nanodendrites before and after the modification of dodecanethoiol.

To further evaluate feasibility and versatility of superwettable electrochemical microchip as a platform toward practical applications, three key parameters closely related to the performance of our superwettable electrochemical microchips including size of droplet, rotation angle of microchip and size of microwell, were chosen to illustrate the ability of performing biodetection. 
a
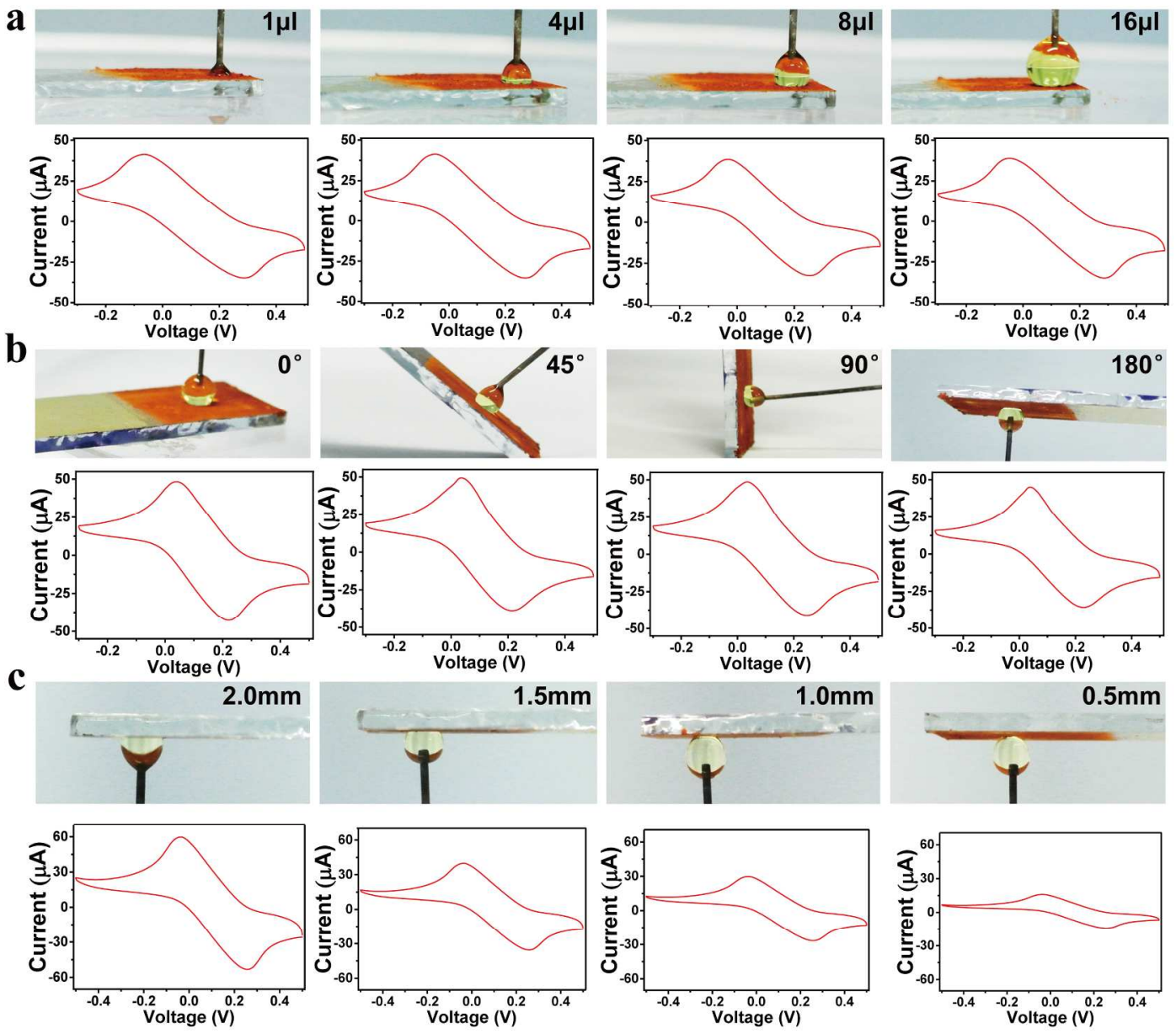

Figure 3: Effect of the microdroplets size, tilting angle and microwell size on electrochemical redox reactions. a) Cyclic voltammetry curves (Scan rate: $100 \mathrm{mV} / \mathrm{s}$ ) of superwettable electrode microwells (diameter: $2 \mathrm{~mm}$ ) with microdroplets volumes of $1,4,8$, and $16 \mu 1$, respectively. b) Rotate the superwettable electrochemical microchip with an angle of $0^{\circ}, 45^{\circ}, 90^{\circ}, 180^{\circ}$ to confirm their stability during the detection processes. c) Effect of microwell size of 0.5, 1.0, 1.5, and $2.0 \mathrm{~mm}$ on electrochemical detection. All the measurements were processed in $0.01 \mathrm{M}$ phosphate buffered solution ( $\mathrm{pH} 7.4$ ) containing $0.1 \mathrm{M} \mathrm{KCl}$ and $5 \mathrm{mM} \mathrm{K}_{3}\left[\mathrm{Fe}(\mathrm{CN})_{6}\right] / \mathrm{K}_{4}\left[\mathrm{Fe}(\mathrm{CN})_{6}\right]$.

Fig. 3a illustrates the capability of our superwettable electrode microwells toward electrochemical measurement with different microdroplet volumes. Briefly, microdroplets volumes of 1, 4, 8, and $16 \mu$ were then carefully added in the microwells (Diameter: $2 \mathrm{~mm}$ ). Due to the superhydrophobic propriety of surrounding area, microdroplets were confined in superhydrophilic microwells and present almost spherical when increasing droplet volume as shown in the optical images. The electrochemical measurement was carried out in $0.01 \mathrm{M}$ phosphate buffered saline $(\mathrm{pH}=7.4)$ containing $0.1 \mathrm{M} \mathrm{KCl}$ and $5 \mathrm{mM}$ potassium ferricyanide/ferrocyanide. Cyclic voltammetry results (Scan rate: 100 $\mathrm{mV} / \mathrm{s}$ ) of microdroplets with of $1,4,8$, and $16 \mu$ are just subtly different, revealing the stability of such superwettable microchip toward biodetection regardless of the droplet size. Fig. 3b demonstrates the adhesive property to microdroplet of such superwettable microchip to confirm its capability toward upside-down measurement during the detection process. In brief, the superwettable electrochemical microchip with a microwell of $2 \mathrm{~mm}$ was firstly horizontally placed, $5 \mu \mathrm{l}$ microdroplet which contained $0.01 \mathrm{M}$ phosphate buffered saline and $0.1 \mathrm{M}$ potassium ferricyanide/ferrocyanide was then carefully added in the microwells $\left(0^{\circ}\right)$. When the superwettable electrochemical microchip are rotated with angles of $45^{\circ}, 90^{\circ}$, and $180^{\circ}$, the water droplets can be anchored at the microwells without dropping down due to the large capillary force of such superhydrophilic microwell as demonstrated in optical images. Cyclic voltammetry curves are almost the same with different tilting angles, revealing the stability of such superwettable microchip. Such non-angle dependent electrochemical device shows great potential in fabricating portable device. In Fig. 3c, the influence of the microwell size on the electrochemical response of superwettable microchip was demonstrated. The electrochemical measurement was carried out in the reversed microchip, which is much more conducive to observe. $5 \mu$ microdroplet (0.01 M phosphate buffered saline and $0.1 \mathrm{M}$ potassium ferricyanide-/ferrocyanide) were carefully added in the reversed microwells. With the microwell sizes decreasing from $2.0 \mathrm{~mm}$ to 0.5 $\mathrm{mm}$, the microwells keeps anchoring microdroplets as shown in optic images. However, the contact area between microdroplet and the microwell has a significant influence on probe-binding capacity and the response signals, in which the signal decrease as the contact area decreases.

For electrochemical detection of miRNA and protein, a twoelectrode system where $\mathrm{Ag} / \mathrm{AgCl}$ acts as both reference and counter electrode is chosen to simplify design and suit the small size of microdroplets, which is a common strategy for low-current and low-volume electrochemical sensing. ${ }^{54}$ Two kinds of typical prostate cancer biomarkers including miRNAs (miRNA-141 and miRNA-375, ${ }^{55,56}$ ) and prostate-specific antigen (PSA), ${ }^{57}$ were chosen to illustrate the ability of performing biodetection to further evaluate its feasibility and versatility as a platform toward sensitive biosensing as demonstrated in Fig. 4a. Such multivariate analysis of the PSA and miRNA levels are able to enhance the performance in detecting prostate cancer. 
a
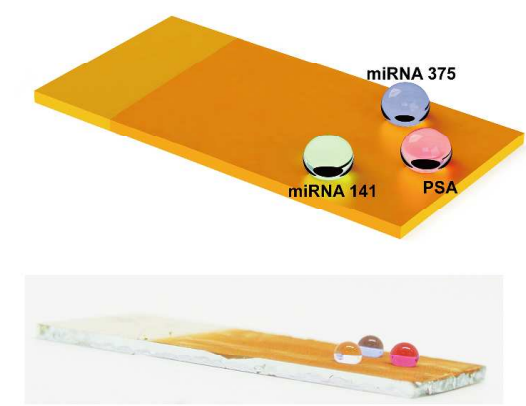

d

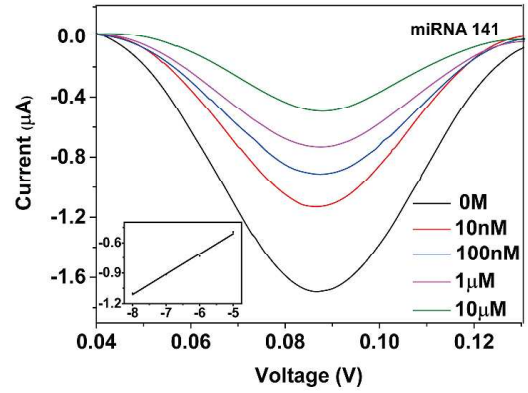

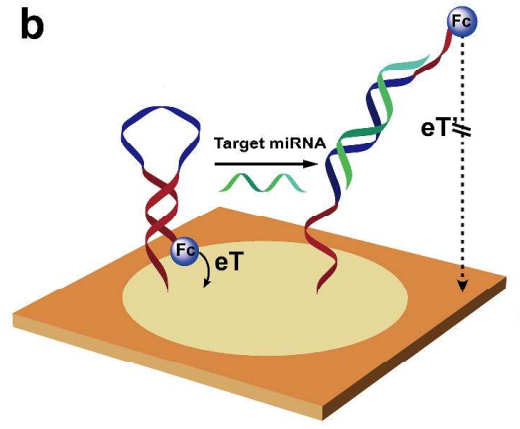

e

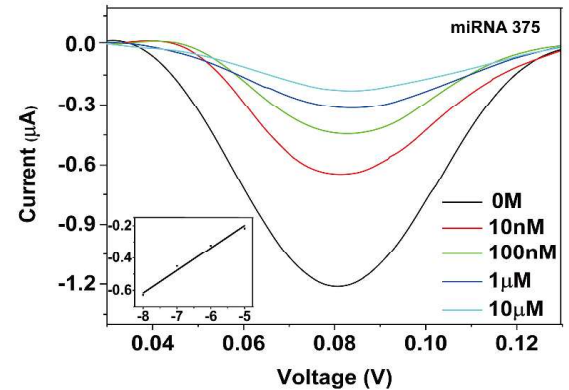

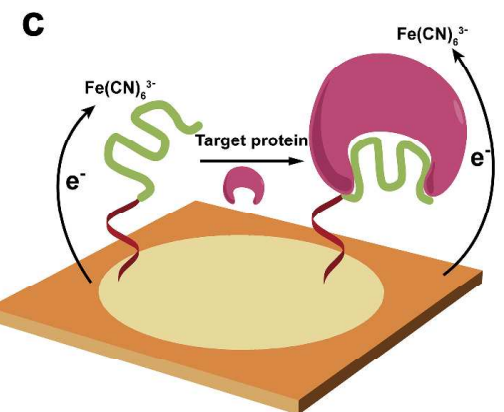

f

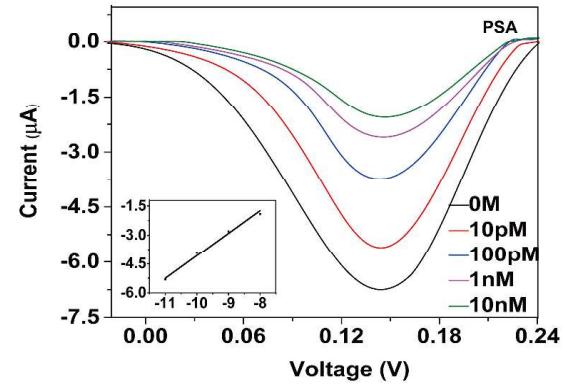

Figure 4: Superwettable microchip toward electrochemical detection of prostate cancer biomarkers. a) Schematic of superwettable microchip toward detection of prostate cancer biomarkers including miRNA-141, miRNA-375 and prostate-specific antigen. b) Schematic of electrochemical miRNA sensor comprises an electrode-bound, redox-reporter-modified DNA for target miRNA detection. c) Schematic of electrochemical aptamer-based sensors (dark blue ribbon) that undergoes a binding-induced conformational change on binding to the target protein (purple sphere). DPV curve for detection of miRNA-141 (d), miRNA-375 (e), and prostate-specific antigen (f).

The mechanism of superwettable microchip for electrochemical miRNA sensing is illustrated in Fig. $\mathbf{4 b}$. The miRNA sensors are comprised of an electrode-bound, redox-reporter-modified DNA probe (purple-blue-purple ribbon) that undergoes a conformational change on binding to the target miRNA (bluish green ribbon). This conformational change alters the positioning of the reporter (Fc) relative to the electrode surface, thereby produces a targetdependent change in current when the sensor is interrogated by differential pulse voltammetry (DPV). The detailed detection processes were carried out at constant temperature and saturated humidity as follows: a $5 \mu \mathrm{L}$ water droplet with $10.0 \mu \mathrm{M}$ DNA probe was dropped in a superhydrophilic microwell (Diameter: 2 $\mathrm{mm}$ ), and incubated at room temperature for probe DNA selfassembly and automatically ringing on nanodendritic gold surface. Prior to measurement, the microchip was immersed in ultrapure water to remove unfixed DNA. Then, $5 \mu \mathrm{L}$ water microdroplet ( $\mathrm{pH}$ 7.0) contains $140 \mathrm{mM} \mathrm{NaCl}, 100 \mathrm{mM} \mathrm{NaClO}$, and target miRNA concentrations of $0 \mathrm{M}, 10 \mathrm{nM}, 100 \mathrm{nM}, 1 \mu \mathrm{M}$ and $10 \mu \mathrm{M}$ were dropped in microwells for $30 \mathrm{~min}$ to ensure the sufficient hybridization of DNA probe and target miRNA. The detection of miRNA-141 and miRNA-375 was performed by DPV (voltage varies from $-0.0 \mathrm{~V}$ to $+0.14 \mathrm{~V}$ ) as demonstrated in Fig. 4d and 4e, respectively. The response signals decrease as the concentration of target miRNA increase. A linear plot of the signal peak point $(0.08 \mathrm{~V})$ versus the target miRNA-141 and miRNA-375 concentration ranging from $10 \mathrm{~nm}$ to $10 \mu \mathrm{M}$ was established and a detection limit at a signal-to-noise ratio of 3 was calculated to be $0.8 \mathrm{nM}$.

The detection of PSA was carried out by immobilizing aptamer onto the superhydrophilic microwell as shown in Fig. 4c. The PSA sensors are comprised of an electrode-bound aptamer (purple-blue ribbon) for binding the target protein (purple sphere). Such protein-aptamer binding alters the positioning of the reporter (potassium ferricyanide) relative to the electrode surface, thereby producing a target-dependent change in current. The detailed detection procedure for target protein detection was carried out almost the same as miRNA: a $5 \mu \mathrm{L}$ water microdroplet $(\mathrm{pH} 7.0)$ containing $1 \mathrm{mM} \mathrm{C}_{11} \mathrm{H}_{12} \mathrm{FeO}, 1 \mathrm{mM} \mathrm{MgCl}$ and $140 \mathrm{mM} \mathrm{NaCl}$, and target PSA concentrations of $0 \mathrm{M}, 10 \mathrm{pM}, 100 \mathrm{pM}, 1 \mathrm{nM}$ and $10 \mathrm{nM}$ were dropped in microwells. Due to the aptamer's specific recognition, the corresponding response signals were gradually decreasing upon the increasing target PSA concentration as demonstrated in Fig. 4f. A linear plot of the signal peak point $(0.014 \mathrm{~V})$ versus concentration of target protein is ranging from $10 \mathrm{pm}$ to $10 \mathrm{nM}$ with a detection limit of $1.0 \mathrm{pM}$.

To evaluate the practical application and the selectivity of the biosensor, the goat serum (containing various proteins, 1:10 diluted with 0.1 M PBS) was used as electrolyte to detect the PSA and miRNA (Detailed in supporting information). ${ }^{58,59}$ The selectivity of the superwettable microchip in serum sample as shown in SI Fig. 3. When immobilizing with detection probe for miRNA-141, the superwettable microchip can just response to target miRNA141 regardless of adding miRNA-375 and PSA (SI Fig. 3a). Meanwhile, the superwettable microchip can only response to target PSA when it functionalized with PSA aptamer (SI Fig. 3b). Such results revealed the potential of this superwettable biosensor toward practical application.

In conclusion, the superwettable microchip sensor described in this study represents a hybrid system that integrates superwettable substrate for microdroplets management with nanodendritic gold electrochemical biosensor for sensitive measurement into single microdroplet detection platform, which overcome limitations of conventional electrochemical sensors. Such microchip is realized via electrochemical deposition for nanodendritic gold structure, dodecanethiol modification for superhydrophobic surface, and template $\mathrm{O}_{2}$ plasma etching for superhydrophilic microwells. Microliter of analytical solution can be utilized to during detection processes due to the superhydrophobicity of the surface. The conductive nanodendritic structures in superhydrophilic microwells can effectively enhance the sensitivity and exhibit a high adhesive property. Such capability allows the superwettable microchip as a biosensing platform in sensitive detection of routine prostate cancer biomarkers including miRNA-375, miRNA-141 and prostate- 
specific antigen. Such superwettable microchip represents a great opportunity to manipulate microdroplets toward precise decease detection based on multivariate analysis on a single microchip.

\section{ASSOCIATED CONTENT}

\section{Supporting Information}

Experimental details, oligonucleotides sequences, electrochemical performance comparison of nanodendritic $\mathrm{Au}$ and bare $\mathrm{Au}$ electrode, additional figures. This material is available free of charge on the ACS Publications website via the Internet at http://pubs.acs.org.

\section{AUTHOR INFORMATION}

\section{Corresponding Author}

*xuliping@ustb.edu.cn;

zhangxueji@ustb.edu.cn;

stwang@mail.ipc.ac.cn;

\section{Author Contributions}

X.T. and S.Y. contributed equally to this work.

\section{ACKNOWLEDGMENT}

The work is supported by National Natural Science Foundation of China (NSFC Grant no. 21475009, 21727815), the Top-Notch Young Talents Program of China, and Beijing Municipal Science \& Technology Commission (Z131102002813058, Z161100000116037), Fundamental Research Funds for the Central Universities (FRF-TP-17-066A1).

\section{REFERENCES}

1. Wang, S. T.; Liu, K. S.; Yao, X.; Jiang, L., Bioinspired Surfaces with Superwettability: New Insight on Theory, Design, and Applications. Chem. Rev. 2015, 115, 8230-8293.

2. Celia, E.; Darmanin, T.; Taffin de Givenchy, E.; Amigoni, S.; Guittard, F., Recent advances in designing superhydrophobic surfaces. J. Colloid Interface Sci. 2013, 402, 1-18.

3. Gauthier, A.; Symon, S.; Clanet, C.; Quere, D., Water impacting on superhydrophobic macrotextures. Nat. Commun. 2015, 6, 8001 .

4. Kreder, M. J.; Alvarenga, J.; Kim, P.; Aizenberg, J., Design of antiicing surfaces: smooth, textured or slippery? Nat. Rev. Mater. 2016, 1, 15003.

5. Liu, M.; Wang, S.; Jiang, L., Nature-inspired superwettability systems. Nat. Rev. Mater. 2017, 2, 17036.

6. Deng, X.; Mammen, L.; Butt, H. J.; Vollmer, D., Candle soot as a template for a transparent robust superamphiphobic coating. Science 2012, $335,67-70$.

7. Li, X. M.; Reinhoudt, D.; Crego-Calama, M., What do we need for a superhydrophobic surface? A review on the recent progress in the preparation of superhydrophobic surfaces. Chem. Soc. Rev. 2007, 36, 1350-1368.

8. Zheng, Y.; Bai, H.; Huang, Z.; Tian, X.; Nie, F. Q.; Zhao, Y.; Zhai, J.; Jiang, L., Directional water collection on wetted spider silk. Nature 2010, 463, 640-643.

9. Lv, J. A.; Liu, Y.; Wei, J.; Chen, E.; Qin, L.; Yu, Y., Photocontrol of fluid slugs in liquid crystal polymer microactuators. Nature 2016, 537, $179-184$

10. Tian, X.; Verho, T.; Ras, R. H., Moving superhydrophobic surfaces toward real-world applications. Science 2016, 352, 142-143.

11. Zhang, X.; Jin, M.; Liu, Z.; Tryk, D. A.; Nishimoto, S.; Murakami, T.; Fujishima, A., Superhydrophobic TiO2 Surfaces: Preparation, Photocatalytic Wettability Conversion, and Superhydrophobic-Superhydrophilic Patterning. J. Phys. Chem. C 2007, 111, 14521-14529.

12. Zahner, D.; Abagat, J.; Svec, F.; Frechet, J. M.; Levkin, P. A., A facile approach to superhydrophilic-superhydrophobic patterns in porous polymer films. Adv. Mater. 2011, 23, 3030-3034.

13. Tian, D.; Song, Y.; Jiang, L., Patterning of controllable surface wettability for printing techniques. Chem. Soc. Rev. 2013, 42, 5184-5209.
14. Gu, Z.-Z.; Fujishima, A.; Sato, O., Patterning of a Colloidal Crystal Film on a Modified Hydrophilic and Hydrophobic Surface Angew. Chem. 2002, 114, 2171.

15. Ito, Y., Surface micropatterning to regulate cell functions. Biomaterials 1999, 20, 2333-2342.

16. Shi, W.; Xu, T.; Xu, L. P.; Chen, Y.; Wen, Y.; Zhang, X.; Wang, S., Cell micropatterns based on silicone-oil-modified slippery surfaces. Nanoscale 2016, 8, 18612-18615.

17. Geyer, F. L.; Ueda, E.; Liebel, U.; Grau, N.; Levkin, P. A., Superhydrophobic-superhydrophilic micropatterning: towards genome-ona-chip cell microarrays. Angew. Chem. Int. Ed. 2011, 50, 8424-8427.

18. Efremov, A. N.; Stanganello, E.; Welle, A.; Scholpp, S.; Levkin, P. A., Micropatterned superhydrophobic structures for the simultaneous culture of multiple cell types and the study of cell-cell communication. Biomaterials 2013, 34, 1757-1763.

19. Oliveira, M. B.; Neto, A. I.; Correia, C. R.; Rial-Hermida, M. I.; Alvarez-Lorenzo, C.; Mano, J. F., Superhydrophobic Chips for Cell Spheroids High-Throughput Generation and Drug Screening. ACS Appl. Mater. Interfaces 2014, 6, 9488-9495.

20. Popova, A. A.; Schillo, S. M.; Demir, K.; Ueda, E.; Nesterov-Mueller, A.; Levkin, P. A., Droplet-Array (DA) Sandwich Chip: A Versatile Platform for High-Throughput Cell Screening Based on Superhydrophobic-Superhydrophilic Micropatterning. Adv. Mater. 2015, 27, 5217-5222.

21. Leite, Á. J.; Oliveira, M. B.; Caridade, S. G.; Mano, J. F., Screening of Nanocomposite Scaffolds Arrays Using Superhydrophobic-Wettable Micropatterns. Adv. Funct. Mater. 2017, 27, 1701219.

22. Parolo, C.; Merkoci, A., Paper-based nanobiosensors for diagnostics. Chem. Soc. Rev. 2013, 42, 450-457.

23. Shang, L.; Cheng, Y.; Zhao, Y., Emerging Droplet Microfluidics. Chem. Rev. 2017, 117, 7964-8040.

24. Neto, A. I.; Demir, K.; Popova, A. A.; Oliveira, M. B.; Mano, J. F.; Levkin, P. A., Fabrication of Hydrogel Particles of Defined Shapes Using Superhydrophobic-Hydrophilic Micropatterns. Adv. Mater. 2016, 28, 7613-7619.

25. Garcia-Cordero, J. L.; Fan, Z. H., Sessile droplets for chemical and biological assays. Lab Chip 2017, 17, 2150-2166.

26. De Angelis, F.; Gentile, F.; Mecarini, F.; Das, G.; Moretti, M.; Candeloro, P.; Coluccio, M. L.; Cojoc, G.; Accardo, A.; Liberale, C.; Zaccaria, R. P.; Perozziello, G.; Tirinato, L.; Toma, A.; Cuda, G.; Cingolani, R.; Di Fabrizio, E., Breaking the diffusion limit with superhydrophobic delivery of molecules to plasmonic nanofocusing SERS structures. Nat. Photonics 2011, 5, 682-687.

27. Lu, L.-Q.; Zheng, Y.; Qu, W.-G.; Yu, H.-Q.; Xu, A.-W., Hydrophobic Teflon films as concentrators for single-molecule SERS detection. $J$. Mater. Chem. 2012, 22, 20986.

28. Shin, S.; Lee, J.; Lee, S.; Kim, H.; Seo, J.; Kim, D.; Hong, J.; Lee, S.; Lee, T., A Droplet-Based High-Throughput SERS Platform on a DropletGuiding-Track-Engraved Superhydrophobic Substrate. Small 2017, 13.

29. Hou, J.; Zhang, H.; Yang, Q.; Li, M.; Jiang, L.; Song, Y., HydrophilicHydrophobic Patterned Molecularly Imprinted Photonic Crystal Sensors for High-Sensitive Colorimetric Detection of Tetracycline. Small 2015, $11,2738-2742$.

30. Wu, T.; Xu, T.; Xu, L. P.; Huang, Y.; Shi, W.; Wen, Y.; Zhang, X., Superhydrophilic cotton thread with temperature-dependent pattern for sensitive nucleic acid detection. Biosens. Bioelectron. 2016, 86, 951-957. 31. Zhang, Y.; Ren, T.; Li, T.; He, J.; Fang, D., Paper-Based Hydrophobic/Lipophobic Surface for Sensing Applications Involving Aggressive Liquids. Adv. Mater. Interfaces 2016, 3, 1600672.

32. Xu, T.; Shi, W.; Huang, J.; Song, Y.; Zhang, F.; Xu, L. P.; Zhang, X.; Wang, S., Superwettable Microchips as a Platform toward Microgravity Biosensing. ACS Nano 2017, 11, 621-626.

33. Hernandez-Perez, R.; Fan, Z. H.; Garcia-Cordero, J. L., EvaporationDriven Bioassays in Suspended Droplets. Anal. Chem. 2016, 88, 73127317.

34. Hou, J.; Zhang, H.; Yang, Q.; Li, M.; Song, Y.; Jiang, L., Bio-inspired photonic-crystal microchip for fluorescent ultratrace detection. Angew. Chem. Int. Ed. 2014, 53, 5791-5795.

35. Yen, T. M.; Zhang, T.; Chen, P. W.; Ku, T. H.; Chiu, Y. J.; Lian, I.; Lo, Y. H., Self-Assembled Pico-Liter Droplet Microarray for Ultrasensitive Nucleic Acid Quantification. ACS Nano 2015, 9, 1065510663.

36. Xu, L. P.; Chen, Y.; Yang, G.; Shi, W.; Dai, B.; Li, G.; Cao, Y.; Wen, Y.; Zhang, X.; Wang, S., Ultratrace DNA Detection Based on the 
Condensing-Enrichment Effect of Superwettable Microchips. Adv. Mater. 2015, 27, 6878-6884.

37. Falde, E. J.; Yohe, S. T.; Colson, Y. L.; Grinstaff, M. W., Superhydrophobic materials for biomedical applications. Biomaterials 2016, 104, 87-103.

38. Shin, S.; Seo, J.; Han, H.; Kang, S. B.; Kim, H.; Lee, T., Bio-Inspired Extreme Wetting Surfaces for Biomedical Applications. Materials 2016, 9,116 .

39. Ueda, E.; Levkin, P. A., Emerging applications of superhydrophilicsuperhydrophobic micropatterns. Adv. Mater. 2013, 25, 1234-1247.

40. Wang, P.; Lin, Z.; Su, X.; Tang, Z., Application of Au based nanomaterials in analytical science. Nano Today 2017, 12, 64-97.

41. Zheng, G.; Patolsky, F.; Cui, Y.; Wang, W. U.; Lieber, C. M., Multiplexed electrical detection of cancer markers with nanowire sensor arrays. Nat. Biotechnol. 2005, 23, 1294-1301.

42. Chen, A.; Chatterjee, S., Nanomaterials based electrochemical sensors for biomedical applications. Chem. Soc. Rev. 2013, 42, 5425-5438.

43. Song, S.; Qin, Y.; He, Y.; Huang, Q.; Fan, C.; Chen, H. Y., Functional nanoprobes for ultrasensitive detection of biomolecules. Chem. Soc. Rev. 2010, 39, 4234-4243.

44. Wang, J., Electrochemical glucose biosensors. Chem. Rev. 2008, 108 , 814-825.

45. Xu, T.; Scafa, N.; Xu, L.-P.; Su, L.; Li, C.; Zhou, S.; Liu, Y.; Zhang, X., Electrochemical Sensors for Nitric Oxide Detection in Biological Applications. Electroanalysis 2014, 26, 449-468.

46. Chen, W.; Cai, S.; Ren, Q. Q.; Wen, W.; Zhao, Y. D., Recent advances in electrochemical sensing for hydrogen peroxide: a review. Analyst 2012, 137, 49-58.

47. Xu, T.; Scafa, N.; Xu, L. P.; Zhou, S.; Abdullah Al-Ghanem, K.; Mahboob, S.; Fugetsu, B.; Zhang, X., Electrochemical hydrogen sulfide biosensors. Analyst 2016, 141, 1185-1195.

48. Fan, C.; Plaxco, K. W.; Heeger, A. J., Electrochemical interrogation of conformational changes as a reagentless method for the sequence-specific detection of DNA. Proc. Natl. Acad. Sci. U.S.A. 2003, 100, 9134-9137. 49. Das, J.; Ivanov, I.; Montermini, L.; Rak, J.; Sargent, E. H.; Kelley, S. O., An electrochemical clamp assay for direct, rapid analysis of circulating nucleic acids in serum. Nat. Chem. 2015, 7, 569-575.
50. Drummond, T. G.; Hill, M. G.; Barton, J. K., Electrochemical DNA sensors. Nat. Biotechnol. 2003, 21, 1192-1199.

51. Wen, W.; Yan, X.; Zhu, C.; Du, D.; Lin, Y., Recent Advances in Electrochemical Immunosensors. Anal. Chem. 2017, 89, 138-156.

52. Zhang, X.; Shi, F.; Yu, X.; Liu, H.; Fu, Y.; Wang, Z.; Jiang, L.; Li, X., Polyelectrolyte multilayer as matrix for electrochemical deposition of gold clusters: toward super-hydrophobic surface. J. Am. Chem. Soc. 2004, 126 , 3064-3065.

53. Soleymani, L.; Fang, Z.; Sargent, E. H.; Kelley, S. O., Programming the detection limits of biosensors through controlled nanostructuring. Nat. Nanotechnol. 2009, 4, 844-848.

54. Gao, W.; Emaminejad, S.; Nyein, H. Y. Y.; Challa, S.; Chen, K.; Peck, A.; Fahad, H. M.; Ota, H.; Shiraki, H.; Kiriya, D.; Lien, D.-H.; Brooks, G. A.; Davis, R. W.; Javey, A., Fully integrated wearable sensor arrays for multiplexed in situ perspiration analysis. Nature 2016, 529, 509-514.

55. Sita-Lumsden, A.; Dart, D. A.; Waxman, J.; Bevan, C. L., Circulating microRNAs as potential new biomarkers for prostate cancer. Br. J. Cancer 2013, 108, 1925-1930.

56. Bryant, R. J.; Pawlowski, T.; Catto, J. W.; Marsden, G.; Vessella, R. L.; Rhees, B.; Kuslich, C.; Visakorpi, T.; Hamdy, F. C., Changes in circulating microRNA levels associated with prostate cancer. $B r . J$. Cancer 2012, 106, 768-774.

57. Perfezou, M.; Turner, A.; Merkoci, A., Cancer detection using nanoparticle-based sensors. Chem. Soc. Rev. 2012, 41, 2606-2622.

58. Liu, J.; Wang, X.; Wang, T.; Li, D.; Xi, F.; Wang, J.; Wang, E., Functionalization of monolithic and porous three-dimensional graphene by one-step chitosan electrodeposition for enzymatic biosensor. ACS Appl. Mater. Interfaces 2014, 6, 19997-20002.

59. Niu, X.; Chen, C.; Zhao, H.; Chai, Y.; Lan, M., Novel snowflake-like Pt-Pd bimetallic clusters on screen-printed gold nanofilm electrode for $\mathrm{H} 2 \mathrm{O} 2$ and glucose sensing. Biosens. Bioelectron. 2012, 36, 262-266. 


\section{$\begin{array}{ll}\text { Page } 7 \text { of } 7 & \text { ACS Sensors }\end{array}$}

1
2
3
4
5
6
7
8
9

For TOC only

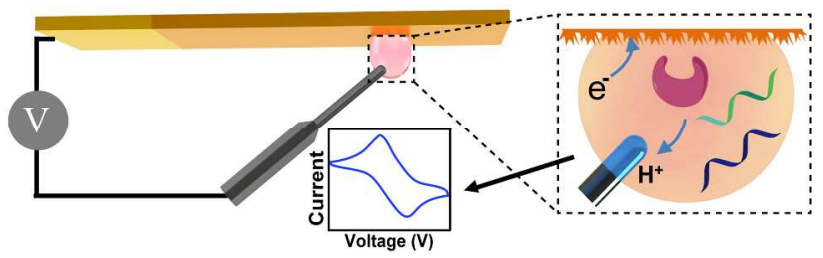

10

11

12

13

14

15

16

17

18

19

20

21

22

23

24

25

26

27

28

29

30

31

32

33

34

35

36

37

39

40

41

42

43

44

45

46

47

48

49

50

51

52

53

54

55

56

57

58

59

60

ACS Paragon Plus Environment 